\title{
Biochemical, Infectious and Foods Profiles in Type 1 Diabetics and Their Siblings of Abidjan District, Côte D'ivoire
}

\author{
Trebissou Aisse Florence Judith, 2, *, Yapo Adou Francis ${ }^{1}$, Yapo-Crezoit Chiaye Antoinette ${ }^{2}$, \\ Bonouman-Ira Ama Benedicte ${ }^{3}$, Fatma Makni Ayedi ${ }^{4}$, Hatem Masmoudi ${ }^{5}$, Lokrou Adrian ${ }^{6}$, \\ Djaman Allico Joseph ${ }^{7}$
}

\author{
${ }^{1}$ Laboratory of Biochemistry-Pharmacodynamics, Faculty of Biosciences, Felix Houphouet Boigny University, Abidjan, Côte d'Ivoire \\ ${ }^{2}$ Pole of Biology Immunity, Pasteur Institute of Côte d'Ivoire, Abidjan, Côte d'Ivoire \\ ${ }^{3}$ Department of Parasitology of Pasteur Institute of Côte d'Ivoire, Abidjan, Côte d'Ivoire \\ ${ }^{4}$ Laboratory of Biochemistry, C. H. U Habib Bourguiba, Sfax, Tunisia \\ ${ }^{5}$ Laboratory of Immunology, C. H. U Habib Bourguiba, Sfax, Tunisia \\ ${ }^{6}$ Division of Diabetes and Endocrinology, C. H. U of Yopougon, Abidjan, Côte d'Ivoire \\ ${ }^{7}$ Department of Medical Biochemistry and Fundamental, Pasteur Institute of Côte d'Ivoire, Abidjan, Côte d'Ivoire
}

\author{
Email address: \\ aisse_judith@yahoo.fr (T. A. F. Judith) \\ *Corresponding author
}

\section{To cite this article:}

Trebissou Aisse Florence Judith, Yapo Adou Francis, Yapo-Crezoit Chiaye Antoinette, Bonouman-Ira Ama Benedicte, Fatma Makni Ayedi, Hatem Masmoudi, Lokrou Adrian, Djaman Allico Joseph. Biochemical, Infectious and Foods Profiles in Type 1 Diabetics and Their Siblings of Abidjan District, Côte D'ivoire. Advances in Biochemistry. Vol. 5, No. 3, 2017, pp. 35-40. doi: 10.11648/j.ab.20170503.11

Received: May 11,2017; Accepted: May 19, 2017; Published: June 27, 2017

\begin{abstract}
This work is to measure certain biochemical parameters and to search the blood, intestinal and pinworm parasites, yeasts and foods parameters in type 1 diabetics and their siblings. The study population is constitute of 28 Type 1 diabetics (TD1) and 59 siblings aged between 5 to 21 years, including 41 boys and 46 girls, a sex ratio of 0.89 . The mean age of T1D was $12.62 \pm 2.75$ years and the mean age of the siblings of diabetic's patients was $12.13 \pm 4.94$ years. TD1 were recruited in C. H. U of Yopougon and Treichville and two NGOs of Côte d'Ivoire. The biochemical parameters were assayed at the laboratory of biochemistry of C. H. U Habib Bourguiba of SFAX, Tunisia. Research of Infectious and foods parameters was carried out Institute Pasteur of Côte d'Ivoire. Study takes place January 2014 to April 2016. Biochemical parameters carried out with Cobas 6000 (Roche / Hitachi). Infectious parameters research was done by direct and Ritchie simplified method, Kato test and scotch anal test. Foods parameters were researched by survey. Phosphorus value was three times greater than normal in certain siblings. There was no difference on the concentration of the biochemical parameters between TD1 and their siblings $(\mathrm{p}>0.05)$. There were presence of blood, intestinal, pinworms parasites and yeast in TD1 and their siblings and unbalanced diet (carbohydrate, protein and lipid) with their siblings $(\mathrm{p}<0.0001)$. TD1 and sibling should be dewormed. Sibling should have balanced diet to avoid clinic diabetes.
\end{abstract}

Keywords: Type 1 Diabetes, Biochemical Parameters, Infection Profile, Food Profile, Côte D'Ivoire

\section{Introduction}

Diabetes is a multifactorial disease also linked to the effect of several genes and environmental factors [1]. Type 1 diabetes (DT1) results from the selective destruction by the immune system of insulin-secreting cells of the pancreas islets of Langerhans. The presence of insulin, detection of autoantibodies, activated $\mathrm{T}$ lymphocytes against antigens expressed by insulin-secreting $\beta$ cells of islets of Langerhans of the pancreas and the occurrence of the disease in subjects expressing molecules of the major histocompatibility 
complex (MHC) make diabetes an autoimmune disease [2-3].

Type 1 diabetes or juvenile insulin-dependent diabetes is a disease that affects more than 31 million people worldwide [4]. It is the final consequence of a slow and progressive process of destruction of endothelial pancreatic islet $\beta$ cells leading to ketoacidosis without treatment [5]. This destruction of $\beta$ cells responsible for insulin production begins with the initiation of the autoimmune reaction and, after several years of evolution, leads to the clinical signs of the disease when the $\beta$-cell mass becomes insufficient for to ensure normoglycemia [6].

Type 1 diabetes (T1D) is a major public health problem due to the often early onset of the disease. The increasing incidence in most populations, the lack of curative treatment, and the heavy burden of complications vascular problems associated with residual hyperglycaemia despite the repeated injections of insulin in treated patients [2]. The number of people with diabetes in the world was 171 million in 2000 , with type 2 diabetes accounting for more than $85 \%$ and 336 million in 2030 [7-8]. In addition, estimates of the number of people with diabetes in the world have increased to 382 million in 2013 and 422 million in 2014 [9-10]. Moreover, according to Anonymous 3, although type 1 diabetes is much rarer than type 2 diabetes, it is also becoming more common [11]. Worldwide, the number of people involved is increasing by an average of $3 \%$ per year. It is mostly children who are affected; around the world, some 86,000 children develop diabetes each year. The prevalence of children with diabetes is highest in Europe. Approximately 497,100 children and adolescents have type 1 diabetes with 79,100 new cases each year among children under 15 years of age [12]. In Africa, 39.1 thousand children aged 0-14 years have type 1 diabetes in 2013 [13]. In Côte d'Ivoire, 1.5-2\% of children and adolescents have type 1 diabetes, compared with $1 \%$ in 1995 [14-15]. In recent years, the mortality rate of type 1 diabetes has grown exponentially. 138,000 people aged 19 to 79 years died of type 1 diabetes in 2011, compared with 1.2 million deaths due to diabetes in 2012 [10-13]. It is an incurable disease that continues to wreak havoc in Africa and particularly in Côte d'Ivoire. However, little attention is paid to this disease despite the many complications and the enormous costs it generates.

In order to reduce the rate of type 1 diabetics in Côte d'Ivoire, the aims of this study was to measure and compare certain biochemical parameters, to research the blood, intestinal and pinworm parasites, yeasts as well as the foods parameters in type 1 diabetics and their siblings.

\section{Material and Method}

\subsection{Material}

\section{Study population}

The study population is constituted of 87 people. It includes known type 1 diabetics (T1D), aged between 5 to 21 years and followed in two diabetic care centers in the district of Abidjan, Côte d'Ivoire. These are the endocrinology department of the CHU of Yopougon and the diabetes clinic of C. H. U of Treichville. Some type 1 diabetics have been recruited from two NGOs, the Diabetic Association of Côte d'Ivoire (DIACI) and the New Diabetic Association of Côte d'Ivoire (NDACI). The study population also consisted of apparently healthy consanguineous siblings of selected type 1 diabetics, also aged between 5 to 21 years. There were 28 T1D and 59 siblings, including 41 boys and 46 girls, a sex ratio of 0.89 . The mean age of T1D was $12.62 \pm 2.75$ years and the mean age of the siblings of diabetic patients was $12.13 \pm 4.94$ years. This cross-sectional study began in January 2014 and ended in April 2016.

Inclusion Criteria

(1) Being type 1 diabetics aged 5 to 21 years

(2) Be declared diabetic between 2007 and 2016

(3) Have at least one non-diabetic brother or sister aged 5 to 21 years

(4) Have a record of type 1 diabetics

(5) Possess a vaccination record

Non-Inclusion Criteria

(1) Being HIV positive

Biological material

The biological material is constituted of total blood samples in dry tube, Saddles and anal scotch taken on in type 1 diabetics and their siblings. The serum was obtained after centrifugation of the total blood at $3000 \mathrm{rpm}$ for 3 minutes.

\subsection{Methods}

\subsubsection{Selection of Type 1 Diabetics and Their Siblings}

It consisted of selecting type 1 diabetics in the $\mathrm{C}$. H. $\mathrm{U}$ of Yopougon and Treichville. Folders of type 1 diabetes (T1D) aged 5 to 21 years were selected. The year of diagnosis of diabetes was between 2007 and 2016. The contacts of the parents of each patient (telephone, mailbox and email) were recorded. Each patient relative was then contacted by telephone. During the conversations, the interest of the study was to explain the importance of early detection of type 1 diabetes in their families, in order to prevent other children from having type 1 diabetes in the Years. It was asked, after a good understanding, to each parent, the existence or not of sibling of the child DT1 aged from 5 to 21 years. Type 1 diabetics who met these conditions were selected. Parents were invited with their children to the various $\mathrm{C}$. H. U, equipped with their vaccination record for taking samples.

\subsubsection{Determination of Triglycerides, Total Cholesterol, HDL-Cholesterol, LDL-Cholesterol, Phosphorus, Magnesium, Calcium, Urea, Creatinine and Glucose}

The total blood of T1D and their siblings collected has been centrifuged at $3000 \mathrm{rpm}$ for $5 \mathrm{~min}$ to obtain the serum. This serum was used to determine the biochemical parameters with Cobas 6000 (Roche/Hitachi) Germany.

\subsubsection{Search of Blood, Intestinal, Anal Parasites, and Yeasts}

Research of blood parasites is made by the embodiment of the drop of thick and blood smear. The aim of the smear is to 
identify the species of plasmodium. The principle of the thick drop and blood smear is based on the technique of microconcentration of a quantity of blood on blade. Noise occurs optical microscope outside the lysed erythrocytes. Parasite density is the number of parasites counted per microliter of blood. This is to count the number of trophozoites to 200 leukocytes. Parasitic density is determined by the ratio:

$\mathrm{D}=\mathrm{A} \times \mathrm{B} / \mathrm{C}$.

$\mathrm{D}$ : parasitic density;

A: Number of trophozoïtes counted for 200 leukocytes;

B: Standard leukocyte Number: 8000 leukocytes/ $\mu 1$ of blood for children under 5 and 6000 leukocytes for more than 5 years;

C: Number of counted leukocytes.

The search of intestinal parasites and yeasts was made following three different methods.

1) The direct method

The principle is based on the physiological saddle-water mixture, read microscopically optic Leica DM 1000, magnification $\mathrm{X} 10$ and $\mathrm{X} 40$. In the presence of protozoan cysts, one drop is added lugol of $2 \%$ solution in the preparation coloring cysts membranes yellow-brown and the cytoplasmic structures and technical nuclear. This technique can search vegetative forms of cysts protozoa, helminth eggs and larvae.

2) Kato technique

The principle is based on the lightening power glycerin. A small amount of stool is covered with an adhesive cellophane coverslip. The mixture is returned against a blotter disposed on the flat surface and with the thumb, a steady pressure is applied until the sample covers an area equal to that of cellophane strip. The preparation is read optical microscope magnification X10 and X40.

3) Technical Ritchie simplied

The principle is based on a combination of sedimentation and the dissolving power of the ether. An amount saddle is diluted to 10 th in water $10 \%$ formol. Ether is added to the solution obtained after filtration. The tube is then centrifuged at $3000 \mathrm{rpm}$ for $5 \mathrm{~min}$. The centrifugation gives four phases arranged from top to bottom. An ethereal phase, a cake topper made of various debris, a formalin phase and the pellet containing the potential parasites. The first 3 phases are discarded and a few drops of saline are added to culot. The entire base is examined under an optical microscope Leica DM 1000 objectives X10 and X40. This technique allows the search of eggs and larvae helminth and protozoan cysts.

The isolation of yeasts was done on the Sabouraud chloranphénicol medium. The identification was to take a colony of yeasts grown on the Sabouraud chloranphénicol medium and suspended in $1 \mathrm{ml}$ of sterile saline. Then, one drop of yeast suspension is transferred to the chromatic Candida medium and is incubated at $37^{\circ} \mathrm{C}$ for $24 \mathrm{~h}$. This medium allows the isolation and differentiation of Candida albicans, Candida tropicalis and Candida krusei based on colour and colony morphology. Candida albicans: pale green, Candida tropicalis: blue-green, Candida krusei: pink, other white-pink species.

Anal scotch test principle

The technique is preferably done in the morning before the toilet and before defecation. A cellophane adhesive fragment or transparent tape is applied using a plastic tube bottom of the radial folds of the previously unfolded anus. The cellophane is then adhered on a slide to be examined by light microscopy. The purpose of this technique is to look for pinworm eggs.

\subsubsection{Search of Foods Parameters: Food Parameters Research Was Done by Questionnaire on Survey Forms}

Method of statistical analysis

The Graph Pad. Prism. V5.01 software was used for statistical analysis of the results and the graphic representation. The data were analyzed using One-Way ANOVA. Turkey's t-test nonparametric was used for the comparison of the variance of different biological parameters between T1D and their siblings. The difference between two variances was significant if $\mathrm{p}<0.05$.

\section{Result}

\subsection{Results of Biochemical Parameters in Type 1 Diabetics and Their Siblings}

Table 1 presents the results of the biochemical parameters obtained during this study. In the lipid profile, mean values of triglycerides, total cholesterol, HDL-cholesterol and LDLcholesterol were within the range of standard values in TD1 and siblings. These values showed no significant differences between TD1 and their siblings. At the micronutrient level, mean values of phosphorus, magnesium and calcium were within the range of normal values in TD1 and their siblings and showed no significant differences. Serum parameters in the kidneys were normal values for urea and creatinine in TD1 and siblings $(p>0.05)$. The mean value of blood glucose in TD1 was $2.85 \pm 0.40$ in TD1, ie twice the normal value and $0.99 \pm 0.47$ in siblings.

Table 1. Biochemical Parameters in type 1 diabetics and their siblings.

\begin{tabular}{llll}
\hline Biochemical parameters & Type 1 diabetics $(\mathbf{n = 2 8})$ & Siblings $(\mathbf{n = 5 9 )}$ & P value \\
\hline Lipid Profil & & & \\
Triglycerides & $1.34 \pm 0.28$ & $1.13 \pm 0.09$ & $\mathrm{P}=0.103>0.05$ \\
Total Cholesterol & $4.48 \pm 0.33$ & $4.26 \pm 0.16$ & $\mathrm{P}=0.124>0.05$ \\
HDL-Cholesterol & $1.16 \pm 0.14$ & $1.33 \pm 0.09$ & $\mathrm{P}=0.0515>0.05$ \\
LDL-Cholesterol & $2.29 \pm 0.28$ & $2.54 \pm 0.14$ & $\mathrm{P}=0,4988>0.05$ \\
Micronutrients & & & $\mathrm{p}=0.703>0.05$ \\
Phosphorus & $1.29 \pm 0.77$ & $1.09 \pm 0.64$ & \\
\hline
\end{tabular}




\begin{tabular}{llll}
\hline Biochemical parameters & Type 1 diabetics $(\mathbf{n}=\mathbf{2 8})$ & Siblings $(\mathbf{n}=\mathbf{5 9})$ & P value \\
\hline Magnesium & $0.81 \pm 0.44$ & $0.88 \pm 0.1$ & $\mathrm{p}=0.931>0.05$ \\
Calcium & $2.49 \pm 0.19$ & $2.44 \pm 0.17$ & $\mathrm{p}=0.696>0.05$ \\
Serum kidney and glycemic parameters & & $\mathrm{P}=0.0576>0.05$ \\
Urea & $3.34 \pm 0.84$ & $2.91 \pm 0.41$ & $\mathrm{P}=0.1808>0.05$ \\
Creatinine & $70.71 \pm 3.73$ & $65.76 \pm 2.73$ & $\mathrm{P}=0.1696>0.05$ \\
Glucose & $2.85 \pm 0.40$ & $0.99 \pm 0.47$ & \\
\hline
\end{tabular}

Normal values (mmol / 1): triglycerides (0.4-2.3), total cholesterol (4-5.2), HDL-cholesterol (0.9-1.45), LDL-cholesterol 0.87-1.45), magnesium (0.66-1.07), calcium (2.15-2.55), urea (2.5-8) mmol / 1, creatinine (62-106) $\mu \mathrm{mol} / \mathrm{L}$, glucose (0.7-1.1) g/ . Significance value: $\mathrm{p}<0.05$.

\subsection{Result of Infectious Factors in Type 1 Diabetics and Their Siblings: Blood, Intestinal, Anal Parasites and Yeast}

Blood parasites of Plasmodium malarae strain were detected in $1 / 28(3.57 \%)$ of type 1 diabetics and Plasmodium falciparum in a $1 / 59(1.69 \%)$ sibling. Their titers were 320 and 120 trophozoites / $\mu$ l of blood, respectively. There is no significant difference between TD1 and their siblings at the level of the blood parasites, because there are as many TD1 as siblings who are infected with blood parasites (Figure 1).

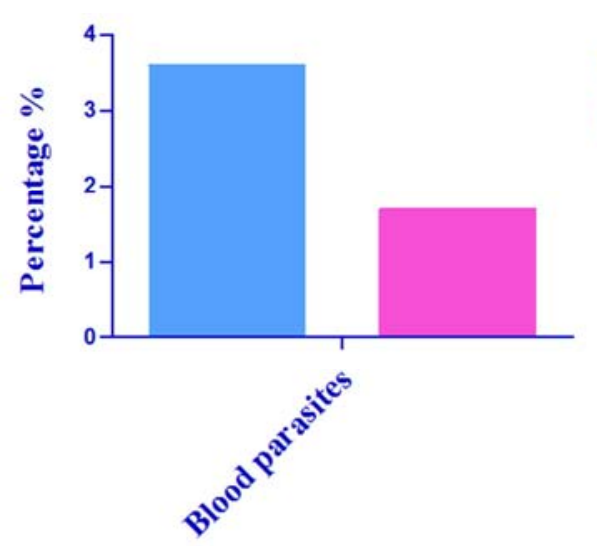

Type 1 diabetics $(n=28)$

Siblings $(\mathrm{n}=59)$

Figure 1. Percentage of blood parasites in type 1 diabetics and their siblings.

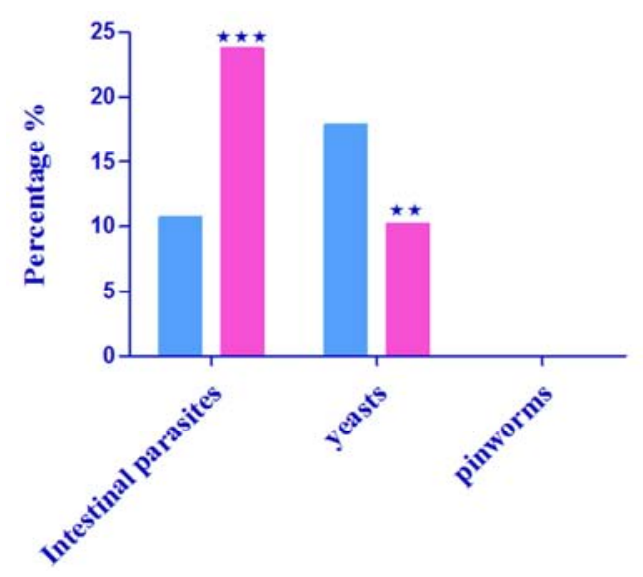

Type 1 diabetics $(\mathrm{n}=28)$

Siblings $(n=59)$

Figure 2. Percentage of onset of intestinal parasites, yeasts and pinworms in type 1 diabetics and their siblings.

Intestinal parasites $=$ Endolimax nana, Entamoeba coli, ascaris and triccephalic egg, giardiasis. Levures $=$ Candida Krusei. Level of significance $*=\mathrm{p}<0.05, * *=\mathrm{p}<0.001$ and $* * *=\mathrm{p}<0.0001$

\subsection{Dietary Factors in Type 1 Diabetics and Their Siblings}

Table 2 shows that the diet of type 1 diabetics differed significantly from that of their siblings in all food groups (carbohydrates, lipid, animal and vegetable proteins). The significant difference varied from $\mathrm{p}<0.0001$ to $\mathrm{p}=0.031<0.05$. 
Table 2. Food consumption rates by TD1 and their siblings.

\begin{tabular}{llllllll}
\hline \multirow{3}{*}{ Foods } & TYPE 1 DIABETICS & \multicolumn{7}{l}{ SIBLINGS } \\
\cline { 2 - 8 } & $\begin{array}{l}\text { High consum } \\
\mathbf{( \% )}\end{array}$ & $\begin{array}{l}\text { Average } \\
\text { consum }(\mathbf{\%})\end{array}$ & $\begin{array}{l}\text { Low consum } \\
\mathbf{( \% )}\end{array}$ & $\begin{array}{l}\text { High consum } \\
\mathbf{( \% )}\end{array}$ & $\begin{array}{l}\text { Average } \\
\text { consum (\%) }\end{array}$ & $\begin{array}{l}\text { Low consum } \\
\text { (\%) }\end{array}$ & $\begin{array}{l}\text { P-value and } \\
\text { significance }\end{array}$ \\
\hline Glu & 25.00 & 53.57 & 21.42 & 32.20 & 36.67 & 31 & $\mathrm{p}<0.0001(\mathrm{~s} * * *)$ \\
Animals Prot & 35.71 & 42.86 & 21.42 & 45.76 & 30.51 & 23,72 & $\mathrm{p}<0.0001(\mathrm{~s} * * *)$ \\
Vegetals Prot & 3.57 & 21.43 & 75.00 & 6.78 & 30.51 & 62,71 & $\mathrm{p}=0.031<0.05(\mathrm{~s} *)$ \\
Lipids & 82,14 & 3.57 & 14.28 & 72.88 & 22.03 & 5 & $\mathrm{p}<0.0001(\mathrm{~s} * * *)$ \\
\hline
\end{tabular}

$\mathrm{Glu}=$ carbohydrate; Prot $=$ Protein; Consom $=$ consumption. Carbohydrate $=$ rice, attieke, Placali, Foutou banana, foutou manioc, Foutou yam, foufou, spaghetti, couscous, fonio, bread, porridge: rice, millet, but fonio, manioc, fritte. Animal proteins $=$ dairy products, meat, fish. Vegetable proteins $=$ raw groundnut, grilled, boiled, sauce, spread, bean: red, green, white. Lipid = seed sauce, seed sauce, oil: dinor, sunflower, olive, aya. High consumption: $7 \mathrm{~J} / 7$, Average consumption: $2 \mathrm{~J} / 7-5 \mathrm{~J} / 7$, Low consumption: $1 \mathrm{~J} / 7$.

Significant difference $(\mathrm{s} *=\mathrm{p}<0.05 ; \mathrm{s} * * *=\mathrm{p}<0.0001)$.

\section{Discussion}

In terms of biochemical parameters, lipid profile results showed that the mean values of triglycerides $(1.34 \pm 0.28$ mmol / 1), total cholesterol (4.48 $\pm 0.33 \mathrm{mmol} / \mathrm{l})$, HDLCholesterol, $16 \pm 0.14 \mathrm{mmol} / \mathrm{l})$ and LDL-Cholesterol (2.29 $\pm 0.28 \mathrm{mmol} / \mathrm{l})$ in type 1 diabetics were within the range of standard values. The results of this study show that type 1 diabetics would have a balanced lipid profile. These results corroborate those of Muchacka et al [16] who found that lipid disorders in children with type 1 diabetes may be present regardless of their metabolic control, but are more pronounced in children with poor control. At the sibling level, results showed that mean values of triglycerides $(1.13 \pm 0.09)$, total cholesterol $(4.26 \pm 0.16)$, HDL-Cholesterol $(1.33 \pm 0.09)$ LDL-Cholesterol $(2.54 \pm 0.14)$ were within the range of standard values, which means that it has a balanced lipid profile.

Micronutrient research in this study population showed that mean calcium levels, Magnesium and phosphorus were in the range of normal values. The results show that type 1 diabetes is not associated with osteoporosis, which induces a urinary increase in phosphate, calcium and magnesium, resulting in a low blood level of these metabolites [17].

Intestinal parasites were present in TD1 and siblings with a significant difference of $p<0.0001$. These results corroborate those of Yasar [18] who found intestinal parasites such as Giardia lamblia, Entamoeba histolitica and taenia in type 1 diabetics.

Yeasts were found in both TD1 and siblings as Costa et al [19] found candidiasis in both TD1 and control populations. The absence of pinworms in the study population is synonymous with their non-participation in the development of type 1 diabetes.

Studies on the diet of diabetics and their siblings have focused on their daily consumed food. These foods have been classified into the major food groups of carbohydrates, lipids and proteins. The nutrition of the members of the study population was also rich in lipid. Indeed, all siblings with autoantibodies had a lipid-rich diet whose metabolic process is related to the degradation of carbohydrates and lipids, both of which are fundamental elements of diabetes mellitus. The lipid metabolism occurring in the pancreas is regulated by insulin. Thus, normal lipid metabolism leads to increase glucose, either in the blood or in glycogenogenesis [20]. Like carbohydrates, lipid consumption increases blood glucose, so it could be associated with the risk of developing type 1 diabetes and thus the onset of diabetes antibodies. These results show that diet plays an important role in triggering autoantibodies of diabetes in the siblings of type 1 diabetics. Therefore this population at risk should have a balanced diet.

\section{Conclusion}

This study has shown the importance of researching biochemical, infectious and dietary parameters in type 1 diabetics and their siblings. The results showed that type 1 diabetics have a balanced biochemical profile. On the other hand, a rise in phosphorus was observed in siblings at values three times higher than normal. The blood glucose level was high in some siblings. Intestinal, blood and yeast parasites were found in type 1 diabetics and their siblings with no pinworms. The research of dietary factors has shown that siblings of diabetics should have a balanced diet to avoid the installation of clinical diabetes.

\section{References}

[1] Tisch R, McDevitt H. Insulin-dependent diabetes mellitus. Cell 1996; 85(3): 291-297.

[2] Boitard C, Mallone R. Diabète de type 1: vers de nouveaux biomarqueurs. Médecine- sciences 2010; 31-41.

[3] Gaborit B. Les anticorps anti ZnT8, nouveaux biomarqueurs du déclin de la fonction béta- cellulaire dans le diabète de type 1. Le coin de la Biblio, Soc Franç Diabète 2016; 4p.

[4] Vieira A, Druelle N, Courtney M, Avolio F, Ben-Othman N, Pfeifer A, Gjernes E, Faurite B, Collombat $\mathrm{P}$, Reprogramming pancreatic cells to $\beta$ cells. Médecine Sciences 2013; 29: 749-755.

[5] Faideau B, Larger E, Lepault F, Carel JC, Boitard C. Role of beta-cells in type 1 diabetes pathogenesis. Diabetes 2005; 54(Suppl. 2): S87-S96.

[6] Carel JC, Boitard C. Pathogénie du diabète de type 1. Option/Bio, Le cahier Scientifique 1998; 218(suppl); 9-11.

[7] Forouhi NG, Wareham NJ. Epidemiology of diabetes. Medicine 2010; 38(11): 602-606. 
[8] Wild S, Roglic G, Anders GA, Sicree R, King H. Global Prevalence of Diabetes: Estimates for the year 2000 and projections for 2030. Diabetes Care 2004; 27(4): 1047-1053.

[9] Forouhi NG, Wareham NJ. Epidemiology of diabetes. Medicine (Abingdon) 2014; 42(12): 698-702.

[10] WHO. Global report on diabetes. 2016 [ONLINE] Available at: http://www.who.int-2016. [Accessed 15 May 2016].

[11] Anonyme 3. Les trois pistes de réflexion. Atlas du diabète de la FID, 7 è éd. Brussel (Belgique) 2016; 144p.

[12] IDF (International Diabetes Federation), 2006- Available at: http://www.idf.org/idf-press-releases-2006/2/10/2016.

[13] IDF (International Diabetes Federation), 2013- Available at: http://www.idf.org/diabetesatlas.

[14] Abodo J. Le diabète en Afrique sub-saharienne. 2013 [ONLINE] Available at: http://congres2013.fatoafrique.org/IMG/pdf/abodo_jacko_ppt _fr.pdf. [Accessed 01 July 2016].

[15] Lokrou A, Katche A V, Timite K M. Diabetes in children and adolescents in Côte d'Ivoire. Rev Fr Endocrinol Clin 1995; 36(6): 571-589.
[16] Muchacka-Bianga M, Deja G, Jarosz-Chobot P, MałeckaTendera E, Kalina M \& Grychtoł M. Evaluation of selected risk factors of atherosclerosis in children with type 1 diabetes mellitus and hypercholesterolemia. Endokrynol Diabetol Chor Przemiany Materii Wieku Rozw 2006; 12(1): 25-30.

[17] Simonen-Tikka M L, Pflueger M, Klemola P, SavolainenKopra C, Smura T, Hummel S, Kaijalainen S, Nuutila K, Natri $\mathrm{O}$, Roivainen $\mathrm{M}$, Ziegler AG. Human enterovirus infection in children at increased risk for type 1 diabetes: the babydiet study. Diabetologia 2011; 54(12): 2995-3002.

[18] Yasar N, Tevfik S, Hatice O. Is There a Predisposition to Intestinal Parasitosis in Diabetic Patients? Diabetes Care 2001; 24(8): 1503-1504.

[19] Costa LA, Branca MA, Silva AMB, Soares R, Mota D, Alves V, Mirante A, Ramos CJ, De Abreu MJ, Santos-Rosa M, Caramelo F. Type 1 diabetes in children is not a predisposing factor for oral yeast colonization. Med Mycol 2016: 1-10.

[20] Roden M, Stingl H, Chandramouli V, Schumann W C, Hofer A, Landau BR, Nowotny P, Waldhäusl W, Shulman GI. Effects of free fatty acid elevation on postabsorptive endogeneous glucose production and gluconeogenesis in humans. Diabetes 2000; 49(5): 701-7. 